\title{
Detection and measurement of land subsidence and uplift using interferometric synthetic aperture radar, San Diego, California, USA, 2016-2018
}

\author{
Justin T. Brandt ${ }^{1}$, Michelle Sneed ${ }^{1}$, and Wesley R. Danskin ${ }^{2}$ \\ ${ }^{1}$ California Water Science Center, United States Geological Survey, Sacramento, CA, USA \\ ${ }^{2}$ California Water Science Center, United States Geological Survey, San Diego, CA, USA \\ Correspondence: Justin T. Brandt (jbrandt@usgs.gov) \\ Published: 22 April 2020
}

\begin{abstract}
Land subsidence associated with groundwater-level declines is stipulated as an "undesirable effect" in California's Sustainable Groundwater Management Act (SGMA), and has been identified as a potential issue in San Diego, California, USA. The United States Geological Survey (USGS), the Sweetwater Authority, and the City of San Diego, undertook a cooperative study to better understand the hydromechanical response of the coastal aquifer system using Interferometric Synthetic Aperture Radar (InSAR) techniques. Three periods of interest were analyzed for this study that correspond to the periods before and after two substantial changes were made to the location and volume of pumpage: (1) April-August 2016 when groundwater levels and land surface elevation were relatively stable during normal pumping, (2) September 2016-May 2017 when groundwater levels recovered and the land surface uplifted during a period of substantially reduced pumping, (3) June 2017October 2018 when groundwater levels declined and land subsidence occurred when pumpage resumed and expanded to new wells. Spatial and temporal characterization of the hydromechanical response to changes in pumpage is important for managing land subsidence. Further study using InSAR techniques, especially when combined with ground-based geodetic and monitoring-well networks, will provide water managers information to help effectively manage groundwater resources as stipulated in the SGMA.
\end{abstract}

\section{Introduction and background}

Groundwater is an important source of water supply for the San Diego metropolitan areas serviced by the Sweetwater Authority (SWA). The SWA is a publicly-owned water agency and provides agricultural, municipal, and domestic water supply for approximately 190000 people within a $93 \mathrm{~km}^{2}$ area. SWA supplies $70 \%$ of demand from local supplies; the remaining $30 \%$ is imported from the Colorado River, State Water Project, or Sacramento-San Joaquin Delta (Sweetwater Authority, 2019). In contrast, local water sources for the greater San Diego area have accounted for only about $10 \%$ of demand; the remaining $90 \%$ is imported (Danskin, 2006). In order to maintain a reliable supply of water and decrease the reliance on imported water, the SWA expanded its Richard A. Reynolds Groundwater Desalination Facility (Sweetweater Authority, 2019). Recent state-wide emphasis on developing alternative water supply has provided the SWA with grant funding to expand its desalination programs, in part by drilling new wells perforated in brackish groundwater that had previously been considered unusable for human consumption (Danskin, 2006). Pumpage from these new wells has the potential to cause groundwaterlevel declines, compaction of the aquifer system, and resultant land subsidence in densely populated areas. Because land subsidence is specifically described as an "undesirable result" in California's Sustainable Groundwater Management Act (SGMA), the SWA and the City of San Diego began a cooperative study with the United States Geological Survey (USGS) to better understand the hydromechanical response of the coastal aquifer system under varying hydrologic conditions. 


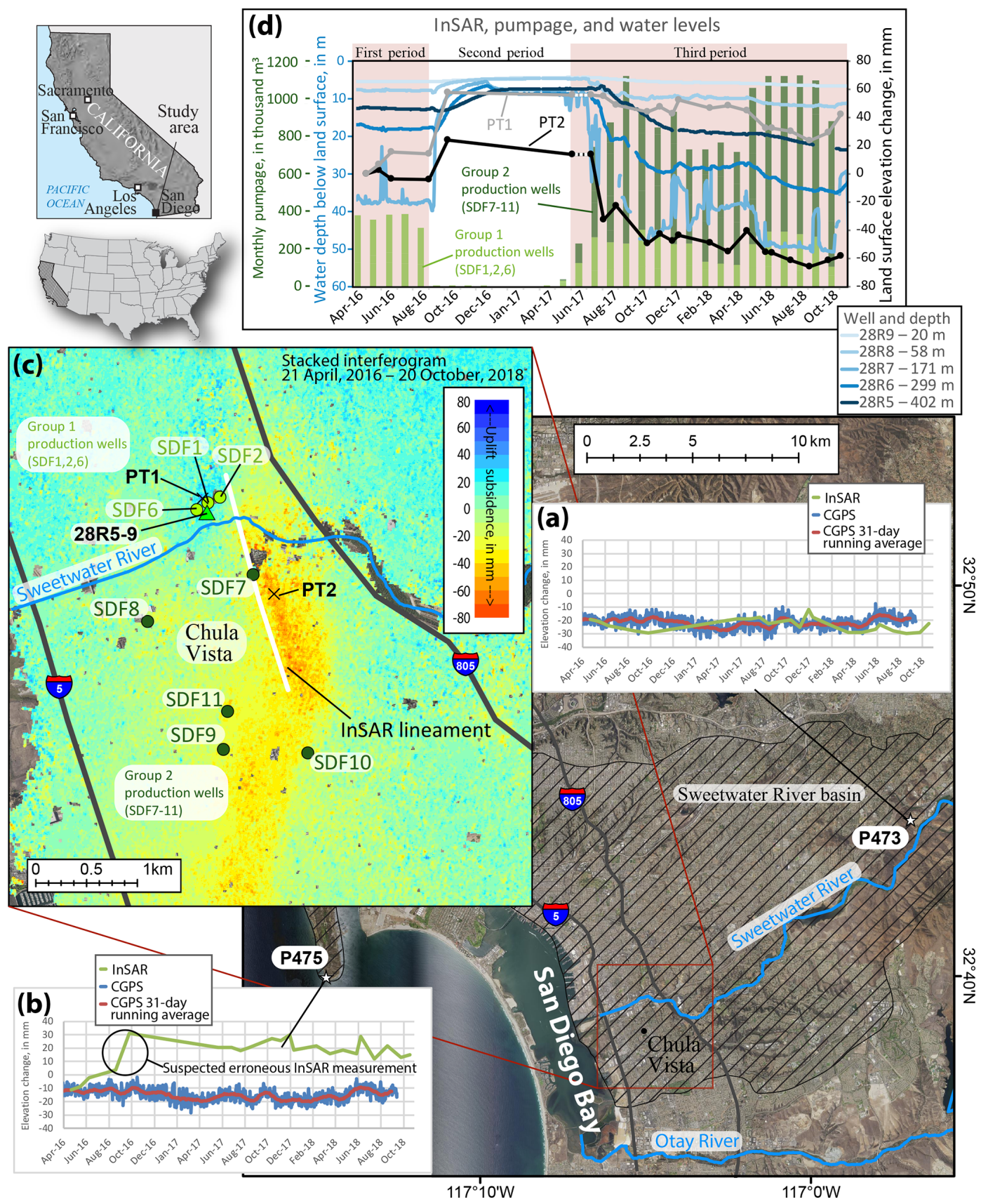

Figure 1. Study area showing Continuous GPS (CGPS) sites, highways, rivers, and Sweetwater River basin, San Diego, California, USA; (a) Continuous GPS (CGPS) and InSAR time series relative to first CGPS data point at P473; (b) CGPS and InSAR time series relative to first CGPS data point at P475; (c) stacked interferogram for 21 April 2016-20 October 2018 (excluding 22 May-27 June 2017) with wells, InSAR time series locations, and InSAR detected lineament; and (d) InSAR timeseries, monthly pumpage volumes and water levels. Sweetwater River Basin modified from Danskin and Church (2005). Basemap is NAIP imagery from 2014, Universal Transverse Mercator projection, zone 11N, North American Datum of 1983 (NAD 83).

\section{Description of study area}

The Sweetwater River basin (Fig. 1) is a major alluvial basin in the San Diego area. The arid basin has a topographic relief that ranges from sea level on the west near San Diego Bay
(Fig. 1), to more than $1500 \mathrm{~m}$ on the east. The groundwater system from which pumpage occurs primarily consists of gravel, sand, silt, and clay (United States Geological Survey, 2019), and comprises two units; a shallow unconsolidated alluvial system estimated to be as much as $100 \mathrm{~m}$ thick, and a 
deeper semi-consolidated system estimated to be as much as $400 \mathrm{~m}$ thick. The contact between the shallow alluvial system and the deeper system is uncertain; however, a geochemical analysis indicated that while production wells extract water from both the shallow and deep systems, a majority of pumpage comes from the deeper part of the coastal aquifer (Danskin and Church, 2005).

\section{Interferometric synthetic aperture radar methods}

Interferometric Synthetic Aperture Radar (InSAR) is a satellite-based remote sensing technique that is used to produce maps of land-surface-elevation change called interferograms. Synthetic Aperture Radar (SAR) imagery is produced by reflecting radar signals off a target area and measuring the 2-way travel time. An interferogram is then generated by differencing (interfering) two SAR images of the same area taken at different times to map the relative change in apparent line-of-site distance (range change) between the ground and the satellite. Range change is then converted to vertical elevation change using the look angle from the satellite to the target area.

InSAR signal quality is dependent on atmospheric effects, topography, and other factors. The principal source of error in the InSAR method applied to the San Diego area results from atmospheric artifacts caused by non-uniform atmospheric water vapor in the form of clouds or fog, and by variable land-surface elevation (higher elevations have less atmosphere). Water vapor slows the radar signal, making the ground appear farther away, and can lead to erroneous deformation interpretations (Zebker et al., 1997). A secondary source of error in the InSAR imagery results from the parallax effect of measuring a point on the ground from two different locations in space (each satellite pass) and becomes more pronounced in areas with steep topographic relief. The relatively flat topography of the Chula Vista area (where land deformation was measured) compared to the surrounding hills and steep cliffs along the coast indicates topography-related errors are not likely to adversely affect land deformation interpretations. Sneed et al. (2014) describe InSAR methodology in more detail.

SAR imagery from the European Space Agency's Sentinel-1A satellite was used for InSAR analysis. Sixty SAR images with acquisition dates between April 2016 and October 2018 were obtained, and more than 125 interferograms were processed for this study. Twenty-one interferograms with time spans ranging from $12 \mathrm{~d}$ to about 8 months were of suitable quality to be used in the analysis. Interferograms in this study had a spatial resolution of approximately $10 \mathrm{~m}$ due to the $10 \mathrm{~m}$ resolution of the digital elevation model used for georeferencing and terrain corrections during processing. The high spatial resolution of InSAR imagery can be coupled with ground-based geodetic monitoring networks to help improve the accuracy of land deformation measure- ments at specific locations and can also be used to identify locations where new geodetic benchmarks could be installed for more detailed analysis.

To assess the quality of InSAR data, Continuous GPS (CGPS) data from Scripps Orbit and Permanent Array Center (2019) and University Navigation Satellite Timing and Ranging Consortium (2019) were compared to InSAR results for 2016-2018 at 4 CGPS sites distributed throughout the San Diego area: two inland sites, and two coastal sites. A representative inland site (P473; Fig. 1a) and a representative coastal site (P475; Fig. 1b) are presented in this report. Day-to-day CGPS height solutions varied by as much as about $30 \mathrm{~mm}$, which is likely the result of variable atmospheric conditions, random walk noise, and other effects not related directly to land-surface-elevation change (Zerbini et al., 2001; Williams et al., 2004; Langbein, 2008). To minimize this high-frequency noise and to enable better comparison between CGPS heights and InSAR measurements, a $31 \mathrm{~d}$ moving average was applied to the CGPS heights; removing day-to-day variations and maintaining seasonal and long-term deformation trends. Vertical changes at the inland CGPS sites compare favourably with InSAR time series; the two datasets show similar trends, and the difference between CGPS and InSAR data over comparable periods is generally less than about $5 \mathrm{~mm}$ (Fig. 1a). InSAR results from the coastal sites compare less favourably with CGPS data, where CGPS and InSAR data can differ by up to about $40 \mathrm{~mm}$ (Fig. 1b). Because the area near P475 has high topographic relief (this site is near a cliff adjacent to the ocean), it is suspected that InSAR results at this site were degraded by spatially localized topographic or atmospheric artifacts that could not be readily removed. Despite the increased deviations, the variance for InSAR and CGPS data for this coastal site are similar, and both datasets indicate relative stability for the majority of the study period. Overall, the comparisons provide confidence in the measurements of land deformation using InSAR.

\section{InSAR reveals deformation in the San Diego area}

The twenty-one interferograms were examined individually for time-series analysis and stacked to generate a deformation history between April 2016-October 2018, with only a single 36 d gap during May-June 2017. Deformation was assumed to be zero during this gap. The resultant stacked interferogram (Fig. 1c) reveals an elongate north-south trending land subsidence feature (about $1.5 \mathrm{~km}$ by $8 \mathrm{~km}$ ) where at least $10 \mathrm{~mm}$ land subsidence occurred. The feature is in a densely populated area approximately bounded by the Sweetwater River on the north, Otay River on the south, San Diego Bay to the west, and Interstate 805 on the east (Fig. 1). The area of maximum land subsidence within this feature occurs at its northern extent near the city of Chula Vista, where as much as about $75 \mathrm{~mm}$ of land subsidence occurred (PT2, Fig. 1c 
and d). A $0.50 \mathrm{~km}$ by $0.25 \mathrm{~km}$ uplift feature is also noted just northwest of the land subsidence feature (Fig. 1c), where as much as about $45 \mathrm{~mm}$ uplift occurred about $1.5 \mathrm{~km}$ north of Chula Vista (PT1, Fig. 1c and d).

The stacked interferogram indicates a roughly northwestsoutheast trending lineament that partially limits the lateral extent of deformation (Fig. 1c). This lineament partially defines the western lateral extent of the land subsidence feature, and the eastern lateral extent of the uplift feature discussed previously. In alluvial basins like those in the San Diego area, the high spatial resolution of InSAR imagery can be used to infer the locations of groundwater-flow barriers where groundwater pumping occurs in compressible deposits and causes differential water levels, and therefore land deformation, across the barrier. Faults commonly are barriers to groundwater flow caused by the juxtaposition of consolidated rocks against water-bearing deposits, or from the displacement of preferential flow paths in water-bearing deposits (Galloway et al., 1999). Further investigation is needed to better understand the mechanisms that limit the lateral extent of differential land deformation.

\section{Relation of pumpage, groundwater levels and land deformation timeseries}

The relation between pumpage, groundwater levels, and land subsidence was analyzed to better understand the hydromechanical response of the coastal aquifer system during periods of varying pumping strategies. In September 2016 and June 2017, the SWA made substantial changes in the location and volume of groundwater pumpage, resulting in three periods of interest for analysis: April-August 2016, September 2016-May 2017, and June 2017-October 2018.

During the first period (April-August 2016), pumpage primarily occurred in a single well field immediately north of the Sweetwater River channel, and less than $1 \mathrm{~km}$ west of Interstate 805 (Group 1 production wells; SDF1, SDF2, and SDF6, Fig. 1c and d). These wells are perforated in both the shallow alluvial deposits and the deeper aquifer. Monthly pumpage volumes were fairly steady; ranging from about 300-400 thousand $\mathrm{m}^{3}$ per month, and groundwater levels were fairly stable. InSAR analysis showed little to no change in land-surface elevation during this time.

During the second period (September 2016-May 2017), pumpage was sharply reduced to enable the SWA to conduct aquifer tests before the activation of new wells. Within the first month of this period, groundwater levels recovered as much as $30 \mathrm{~m}$, and as much as about $45 \mathrm{~mm}$ of uplift occurred near the Group 1 well field (PT1, Fig. 1c and d). After the rapid water-level recovery and uplift, groundwater levels and the land-surface elevation remained fairly stable through May 2017.

During the third period (June 2017-October 2018), pumpage resumed in the existing well field and began in five new spatially distributed wells (Group 2 production wells; SDF7-SDF11, Fig. 1c and d) that were drilled within about $2.5 \mathrm{~km}$ south of the Group 1 well field. These wells are mostly perforated in the deeper system. Pumpage was more than twice that of the first period (about 750-1100 thousand $\mathrm{m}^{3}$ per month during winter and summer periods, respectively). Within about the first four months of this period (June to October 2017), water levels declined up to about $35 \mathrm{~m}$, and interferograms indicate about $65 \mathrm{~mm}$ of land subsidence occurred (PT2; Fig. 1c and d). Interferograms and water-level records during October 2017-October 2018 indicate variable land-surface deformation and water levels that correlate with seasonal changes in pumpage. An increase in pumpage generally translated to water-level decline and land subsidence, and a decrease in pumpage generally translated to water-level recovery and either a slowing of subsidence rates or uplift. The net effect during October 2017October 2018 was an additional $5 \mathrm{~m}$ of water level decline and about $10 \mathrm{~mm}$ of land subsidence. Water levels in wells of various depths indicated a response to the changes in pumpage; however, wells with depths between about 150 and $300 \mathrm{~m}$ (28R5, 28R6, Fig. 1d) showed the greatest variability, which is expected because the majority of pumpage occurs in this deeper portion of the coastal aquifer. Water levels for these wells reached their lowest recorded values (over their less than 10 year history) in October 2018 (Fig. 1d).

\section{Conclusions}

Groundwater is an important source of agricultural, municipal, and domestic water within the San Diego area. Recently, the SWA increased the development of brackish groundwater resources to supplement their local water supply in an effort to maintain a reliable supply of water and decrease the reliance on imported water. Spatial and temporal characterization of the hydromechanical response to changes in pumpage is important to effectively manage water resources as stipulated in the SGMA. A maximum of about $45 \mathrm{~mm}$ of uplift and about $75 \mathrm{~mm}$ of land subsidence occurred as a response to changes in the location and volume of pumpage, and the lateral extent of deformation is partially controlled by a lineament that could be a barrier to groundwater flow.

Especially when combined with a ground-based geodetic and monitoring-well network, InSAR techniques will provide water managers information to help effectively manage groundwater. Because the coastal aquifer system in the San Diego area responded quickly to changes in pumpage, future changes to water management practices will likely cause near immediate effects. Further study is necessary to fully understand the hydromechanical response to changes in pumpage and whether the land-surface deformation is likely to be permanent or recoverable. 
Data availability. Continuous GPS data used in this report is available from Scripts Orbit and Permanent Array Center (2019) and the University Navigation Satellite Timing and Ranging Consortium (2019). Water level data used in this report is available from the US Geological Survey's National Water Information System through the USGS's San Diego Hydrology Project website (2019). Pumpage data was supplied by the Sweetwater Authority. Synthetic Aperture Radar data from the European Space Agency was obtained through the Alaska Satellite Facility (2019).

Author contributions. JB conducted most of the data processing and analyses, and oversaw manuscript preparation. MS provided supervisory oversight and expert analysis, and contributed to manuscript preparation. WD provided background information and expert analysis, and served as the primary point of contact between the US Geological Survey and the Sweetwater Authority and the City of San Diego.

Competing interests. The authors declare that they have no conflict of interest.

Special issue statement. This article is part of the special issue "TISOLS: the Tenth International Symposium On Land Subsidence - living with subsidence". It is a result of the Tenth International Symposium on Land Subsidence, Delft, the Netherlands, 17-21 May 2021.

Acknowledgements. The authors thank the Scripps Orbit and Permanent Array Center and the University Navigation Satellite Timing and Ranging Consortium for allowing free access to continuous Global Positioning System data. We thank the City of San Diego for their support and the Sweetwater Authority for their support and providing pumpage data. The authors also recognize the European Space Agency for making the SAR data used for this report freely available, and the Alaska Satellite Facility for maintaining data archives from which data were accessed.

\section{References}

Alaska Satellite Facility: Synthetic Aperture Radar Datapool, available at: https://datapool.asf.alaska.edu, last access: 24 July 2019.

Danskin, W. R.: Brackish ground water: Defining this new resource for coastal San Diego County, in: Groundwater Resources Association 15th annual conference, 21-22 September 2006, San Diego, California, available at: https://ca.water. usgs.gov/sandiego/pdfs/danskin_brackish_gw.pdf (last access: 6 August 2019), 2006.

Danskin, W. R. and Church, C. D.: Determining age and vertical contribution of ground water pumped from wells in a small coastal river basin. A case study in the Sweetwater River Valley, San Diego County, California, US Geological Survey Open-File Report 2005-1032, US Geological Survey, Reston, Virginia, p. 4, 2005.

Galloway, D. L., Jones, D. R., and Ingebritsen, S. E. (Eds.): Land subsidence in the United States, US Geological Survey Circular 1182, US Geological Survey, Reston, Virginia, p. 175, https://doi.org/10.3133/cir1182, 1999.

Langbein, J.: Noise in GPS displacement measurements from Southern California and Southern Nevada, J. Geophys. Res., 113, B05405, https://doi.org/10.1029/2007JB005247, 2008.

Scripps Orbit and Permanent Array Center: Time Series Data, available at: ftp://garner.ucsd.edu/, last access: 7 February 2019.

Sneed, M., Brandt, J. T., and Solt, M.: Land subsidence, groundwater levels, and geology in the Coachella Valley, California, 1993-2010, US Geological Survey Scientific Investigations Report 2014-5075, US Geological Survey, Reston, Virginia, p. 62, https://doi.org/10.3133/sir20145075, 2014.

Sweetwater Authority: Strategic Plan Update, 2017, available at: https://www.sweetwater.org/, last access: 6 August 2019.

United States Geological Survey: San Diego Hydrology Project, available at: https://ca.water.usgs.gov/projects/sandiego/, last access: 19 August 2019.

University Navigation Satellite Timing and Ranging Consortium: GPS/GNSS Data Access Methods, available at: https://www. unavco.org/, last access: 31 January 2019.

Williams, S. D. P., Bock, Y., Fang, P., Jamason, P., Nikolaidis, R. M., Prawirodirdjo, L., Miller, M., and Johnson, D. J.: Error analysis of continuous GPS position time series, J. Geophys. Res., 109, B03412, https://doi.org/10.1029/2003JB002741, 2004.

Zebker, H. A., Rosen, P. A., and Hensley, S.: Atmospheric effects in interferometric synthetic aperture radar surface deformation and topographic maps, J. Geophys. Res., 102, 7547-7563, 1997.

Zerbini, S., Richter, B., Negusisi, M., Romagnoli, C., Simon, D., Domenichini, F., and Schwahn, W.: Height and gravity variations by continuous GPS, gravity, and environmental parameter observations in the southern Po Plain, near Bologna, Italy, Earth Planet. Sc. Lett., 192, 267-279, 2001. 